\title{
THE D-XYLOSE ABSORPTION TEST IN INFANCY
}

\author{
BY \\ W. MORRICE MCCRAE \\ From the Royal Hospital for Sick Children, Glasgow
}

(RECEIVED FOR PUBLICATION JUNE 17, 1963)

In recent years the d-xylose test has become a standard technique in the investigation of small bowel absorptive function. It has proved to be a simple and reliable procedure of particular value in distinguishing primary small bowel disease from other causes of malabsorption where the defect is essentially one of intraluminal digestion.

The test is therefore potentially of value in the paediatric age-group in the differential diagnosis of disorders that produce the 'coeliac syndrome'. It might also provide a useful screening test for primary malabsorption in such other contexts as anaemia and failure to thrive.

The successful use of the test has been reported in children (Clark, 1962; Jones and di Sant'Agnese, 1963). Experience has shown, however, that technical difficulties, especially in the accurate collection of a five-hour specimen of urine, limit the usefulness of the test in infancy. Since this is an age at which the 'coeliac syndrome' frequently presents, special modification of the test has been found necessary for these patients.

\section{Theoretical Considerations}

In carrying out the d-xylose absorption test in adults the usual procedure is to give $25 \mathrm{~g}$. d-xylose in $250 \mathrm{ml}$. water to the fasting patient. The urine secreted in the following five hours is collected and its d-xylose content estimated. In the normal subject it has been shown that of any dose of d-xylose given by mouth some $65 \%$ is rapidly absorbed from the small intestine (Christiansen, Kirsner and Ablaza, 1959). Of the d-xylose absorbed $40 \%$ is rapidly excreted in the urine (Wyngaarden, Segal and Foley, 1957) and this absorption is virtually complete five hours after ingestion (Brien, Turner, Watson and Geddes, 1952). The urine collected in the five hours of the test therefore contains $26 \%$ of the oral dose.

In idiopathic steatorrhoea it has been found that less d-xylose is absorbed from the intestine and that this absorption is delayed (Fourman, 1948). In this, and other primary malabsorptive states, the five-hour urine collection therefore contains significantly less than $26 \%$ of the oral dose, giving good separation from normal values.

In adapting this test for children, Wolfish, HildickSmith, Ebbs, Connell and Sass-Kortsak (1955) suggested a dose of $0.5 \mathrm{~g}$. xylose/lb. body weight. This, however, frequently produces loose stools even in some normal subjects. Clark (1962) has successfully used $15 \mathrm{~g} . / \mathrm{m} .{ }^{2}$ body surface, and Jones and di Sant'Agnese (1963) avoided symptoms by giving $0.5 \mathrm{~g} . / \mathrm{kg}$. body weight.

However, if $65 \%$ of the d-xylose given is absorbed in the normal subject, irrespective of the size of the dose or the weight of the patient, there seems no reason to complicate the test by varying the dose for the individual child. I have used $5 \mathrm{~g}$. in all patients, with no side-effects.

The main difficulty in performing this test is the accurate collection of a five-hour specimen of urine. Because of the possibility of infection, catheterization is not justified, especially in infancy where the risk of trauma is increased. Moreover, a child cannot always be expected to end a collection period with a completely empty bladder. Since the total volume of urine secreted by an infant in five hours is small, the failure to collect even the few $\mathrm{ml}$. of urine remaining in an incompletely emptied bladder will cause a significant error in the calculation of the amount of d-xylose excreted. This point is demonstrated in the present investigation.

The answer to this problem seemed to be to prolong the collection for 24 hours. In the normal subject it has been shown that d-xylose excretion is almost completed in five hours. There should, therefore, be no considerable difference between the d-xylose content of a full 24-hour collection and that of an accurate five-hour collection. Minor inaccuracies in collection at the end of a 24-hour period should prove unimportant.

However, it has been shown (Fourman, 1948) that in idiopathic steatorrhoea the low xylose 


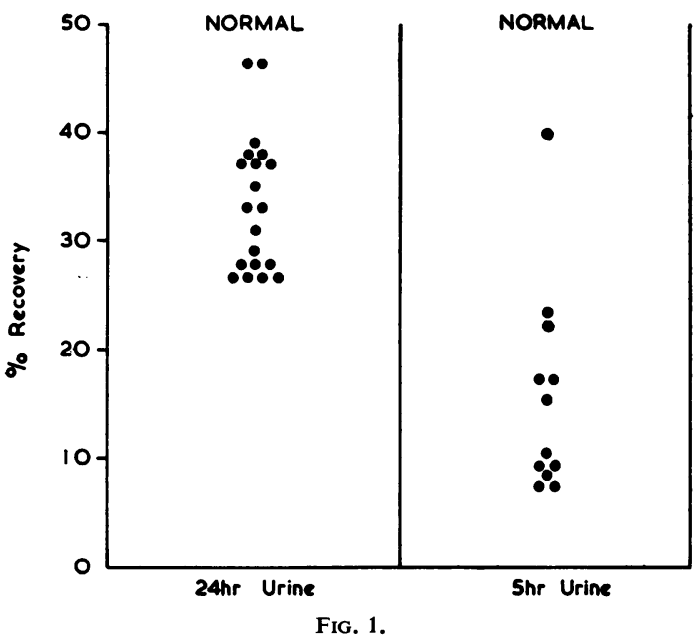

excretion is due to an absorption that is both diminished and delayed. By prolonging the collection period to 24 hours the effect of delayed absorption disappears. It seemed possible, therefore, that by performing the test with 24-hour collections of urine the separation between normals and abnormals might be obscured.

This investigation was carried out to confirm the suitability of a $5 \mathrm{~g}$. dose for infants and to observe the degree of separation between normal and abnormal values when the urine was collected for 24 hours.

\section{Method}

The subjects were fasted overnight. At 7 a.m. 5 g. $\mathrm{d}$-xylose was given in $100 \mathrm{ml}$. water, and all urine was

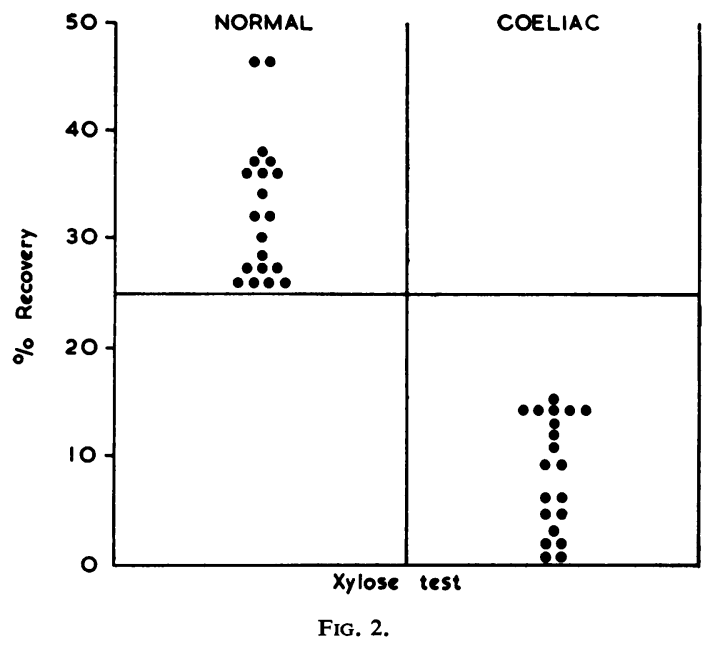

collected for the following 24 hours. The patient was encouraged to drink more water but remained fasting until noon.

From boys the urine was collected into a length of Paul's tubing attached to the penis. For girls the method adopted was that described by Baldwin, Clayton, Jenkins, Mitchell and Renwick (1962).

The urinary d-xylose was estimated by the method of Roe and Rice (1948).

The patients studied were 20 children suffering from coeliac disease, whose ages ranged from 7 months to 2 years. All had the characteristic clinical and radiological features of the disease and in every case jejunal biopsy showed severe or complete villous atrophy.

The controls were 20 children in the same age-group who had been admitted to hospital usually because of

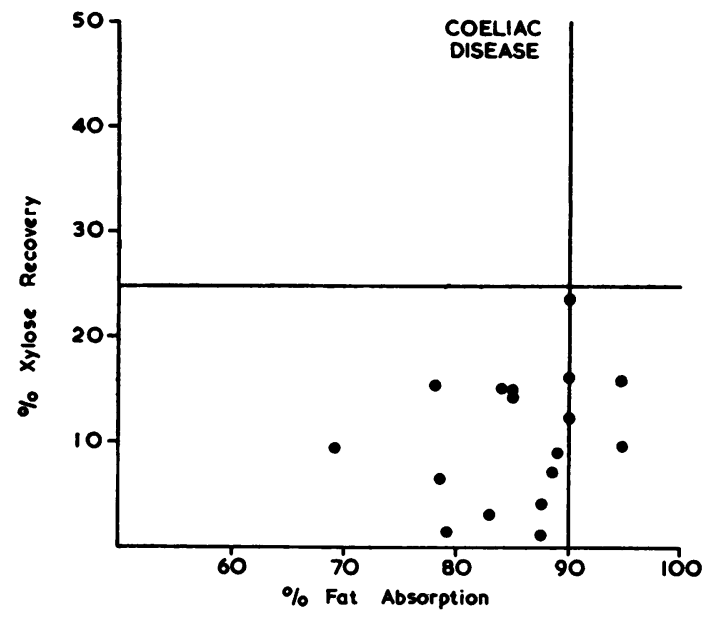

FIG. 3.

respiratory infections. . None of these children showed any evidence of gastro-intestinal, liver or renal abnormality.

\section{Results}

The effect of prolonging the collection of urine to 24 hours in normal children is shown in Fig. 1. When the urine was collected for 24 hours, these control subjects were found to excrete the amount of d-xylose that would have been theoretically expected.

In the same subjects, when the urine was collected for five hours only, the scatter of results extended outside the expected normal range. This can be explained most simply as the result of incomplete bladder emptying.

In Fig. 2 the results of the d-xylose test are shown for patients with coeliac disease. It can be seen 
that all normal subjects excreted at least $25 \%$ of the ingested d-xylose. Patients with coeliac disease all excreted less than $16 \%$. Although the effect of delayed absorption had been removed the separation from normal values remained adequate.

In 17 patients it was possible to relate the results of the d-xylose test with the absorption of fat as shown by a five-day fat balance. The results are shown in Fig. 3. Taking $90 \%$ fat retention as the lower limit of normal, 15 patients had steatorrhoea as well as diminished xylose absorption. Apart from this general agreement there was no correlation between the degree of failure of fat absorption and failure of d-xylose absorption.

\section{Summary}

A modification of the d-xylose absorption test for infants is described. A $5 \mathrm{~g}$. dose of d-xylose was given to all patients and urine was collected for 24 hours thereafter.

Normal subjects were found to excrete more than $25 \%$ of the oral dose. Patients with active coeliac disease gave significantly lower values and there was no overlap between the groups.
I wish to thank Dr. R. A. Shanks for his advice and for permission to study patients in his wards. I also wish to thank Miss O. Peden, B.Sc., for her generous assistance with the biochemical estimations.

\section{REFERENCES}

Baldwin, E. M., Clayton, B. E., Jenkins, P., Mitchell, J. and Renwick, A. G. C. (1962). Collection of urine and faeces in children, with a note on fat balances. Arch. Dis. Childh., 37, 488.

Brien, F. S., Turner, D. A., Watson, E. M. and Geddes, J. H. (1952) A study of carbohydrate and fat absorption from the normal and diseased intestine in man. I. The absorption and excretion of d-xylose. Gastroenterology. 20, 287.

Christiansen, P. A., Kirsner, J. B. and Ablaza, J. (1959). D-xylose and its use in the diagnosis of malabsorptive states. Amer. $J$. Med., 27, 443.

Clark, P. A. (1962). The use of the d-xylose excretion test in children. Gut, 3, 333.

Fourman, L. P. R. (1948). The absorption of xylose in steatorrhoea Clin. Sci., 6, 289.

Jones, W. O. and di Sant'Agnese, P. A. (1963). Laboratory aids in the diagnosis of malabsorption in pediatrics. II. Xylose absorption test. J. Pediat., 62, 50.

Roe, J. H. and Rice, E. W. (1948). A photometric method for the determination of free pentoses in animal tissues. J. biol. Chem., $173,507$.

Wolfish, M. G., Hildick-Smith, G. J., Ebbs, J. H., Connell, M. L. and Sass-Kortsak, A. (1955). The d-xylose tolerance test: a measure of intestinal absorption in normal and dystrophic infants. A.M.A. Amer. J. Dis. Child., 90, 609.

Wyngaarden, J. B., Segal, S. and Foley, J. B. (1957). Physiological disposition and metabolic fate of infused pentoses in man. $J$. clin. Invest., 36, 1395. 